\title{
UTILIZAÇÃO DE PROBIÓTICO E ANTIBIÓTICO NO CULTIVO DE PÓS-LARVAS DO CAMARÃO BRANCO Litopenaeus vannamei
}

\author{
MARCELO REGO, EMANUELL SILVA, NATHALIA CALAZANS, JOANA VOGELEY, ROBERTA NERY, ROBERTA SOARES, \\ SILVIO PEIXOTO \\ Universidade Federal Rural de Pernambuco - Departamento de Pesca e Aquicultura - Laboratório de Tecnologia em Aquicultura, R. Dom \\ Manoel de Medeiros, s/n,. Dois Irmãos, 52171-900, Recife, PE, Brasil - mar_soar@yahoo.com.br
}

\begin{abstract}
RESUMO
O estudo teve como objetivo comparar o efeito da utilização de probiótico e antibiótico no cultivo de pós-larvas do camarão branco Litopenaeus vannamei. O experimento consistiu de três tratamentos com quatro repetições cada, correspondendo a um tratamento biológico (TB), onde foi adicionado probiótico (Bacillus spp.), tratamento químico (TQ), com adição de antibiótico (eritromicina + formalina) e controle (TC), sem adição de nenhum produto na água de cultivo. Pós-larvas no primeiro dia após a metamorfose (PL1) foram estocadas na densidade de 50 pós-larvas L-1 em cada recipiente experimental de 5 litros. $O$ experimento teve duração de 10 dias, onde diariamente foram monitorados os parâmetros de qualidade de água e ao final foram feitas análises morfológicas dos animais. A concentração presuntiva de Vibrio spp. na água e nas pós-larvas foi quantificada no início e final do experimento. Não houve diferença significativa quanto aos parâmetros de qualidade de água entre os tratamentos. Da mesma forma, não foram observadas diferenças significativas entre os tratamentos quanto ao peso final $(2,31$ a $2,67 \mathrm{mg})$, comprimento final $(7,55$ a $7,68 \mathrm{~mm})$ e sobrevivência dos camarões $(74,8$ a $77,7 \%)$. Porém, as concentrações presuntivas finais de Vibrio spp. na água de cultivo e nas pós-larvas foram reduzidas significativamente com a utilização de probiótico (TB) comparado com os outros tratamentos. Os resultados sugerem que o emprego do probiótico Bacillus spp. tem grande potencial para substituir o antibiótico eritromicina e formalina no cultivo de pós-larvas de $L$. vannamei, com possíveis benefícios para a sanidade das pós-larvas cultivadas, além de seguir princípios de aquicultura responsável.
\end{abstract}

PALAVRAS CHAVE: larvicultura, camarão marinho, probiótico, Vibrio.

\section{ABSTRACT}

The use of probiotic and antibiotic in the culture of Litopenaeus vannamei post-larvae.

The study compared the effect of the use of probiotic and antibiotic in the culture of white shrimp Litopenaeus vannamei postlarvae. The experiment consisted of three treatments with four replicates each, corresponding to a biological treatment (TB), where it was added probiotic (Bacillus spp.), chemical treatment (TQ) with the addition of antibiotic (erythromycin + formalin) and control (CT) without addition of any products in the culture water. Postlarvae in the first day after metamorphosis (PL1) were stocked at a density of 50 postlarvae L-1 in each of the 5 liter experimental containers. The experiment lasted 10 days, water quality parameters were daily monitored and at the end of the experiment morphological analysis of the animals were performed. The presumptive concentration of Vibrio spp. in the water and postlarvae was measured at the beginning and final of the experiment. There was no significant difference in the water quality parameters among treatments. Similarly, no significant difference among treatments was observed for the final weight $(2.31$ to $2.67 \mathrm{mg})$, final length $(7.55$ to $7.68 \mathrm{~mm})$ and survival of shrimp (74.8 to $77.7 \%)$. However, the final presumptive concentrations of Vibrio spp. in the water and postlarvae were significantly reduced with the use of probiotic (TP) compared with the other treatments. The results suggest that the use of probiotic Bacillus spp. has great potential to replace the antibiotic erythromycin in the culture of $L$. vannamei postlarvae, with potential benefits to the postlarvae health and following the principles of responsible aquaculture.

KEYWORDS: larviculture, marine shrimp, probiotic, Vibrio.

\section{INTRODUÇÃO}

Nas últimas décadas, diversas doenças infecciosas vêm provocando diminuição na produção de Litopenaeus vannamei (Gullian et al., 2004). Durante a fase de larvicultura, as doenças provocadas por bactérias são tidas como a maior causa de mortalidade (Wyban \& Sweeney, 1991), dentre estas, as do gênero Vibrio vem sendo as mais associadas com essa problemática (Ruangpan \& Kitao, 1991).

As bactérias do gênero Vibrio são consideradas importantes, uma vez que têm grande capacidade de infectar diversos organismos aquáticos, como os camarões peneídeos (Lightner, 1993). No entanto, existem espécies de Vibrio que são caracterizadas tanto como benéficas quanto patogênicas para o cultivo de camarões peneídeos. Em estudos realizados com estas bactérias, Gomez-Gil et al. (2000) caracterizaram o
Vibrio alginolyticus como benéfico ao L. vannamei, enquanto Lee et al. (1996) classificaram essa mesma espécie como patogênica ao camarão Penaeus monodon. Para a espécie luminescente Vibrio harveyi, sua presença em tanques de cultivo vem sendo associada como causadora de doenças e de muitas perdas durante a larvicultura de peneídeos (Vandenberghe et al., 1999).

$\mathrm{Na}$ tentativa de controlar infecções bacterianas, ou mesmo da presença de potenciais bactérias patógenas nos sistemas de larvicultura, a utilização de componentes antimicrobianos (antibióticos) vem sendo realizada principalmente na América Latina e no Sudeste Asiático, onde existem poucas restrições para o uso destes produtos (Gomez-Gil et al., 2000). Entretanto, o emprego de antibióticos tem um sucesso limitado na prevenção ou cura das doenças em animais aquáticos (Ravi et al., 2007). Muitas vezes, o antibiótico 
é aplicado como tratamento profilático, mesmo sem a evidência de algum patógeno, esse fato possibilita a resistência dos víbrios ou de outras bactérias aos antibióticos, aumentando a virulência desses patógenos (Moriarty, 1999).

Como uma estratégia no controle de doenças, o uso de bactérias benéficas (probióticos) tem sido sugerido em substituição ao uso de antibióticos (Gatesoupe, 1999; Ravi et al., 2007). O termo probiótico foi definido por Gatesoupe (1999) para aquelas células microbianas que são administradas de modo a entrar no trato gastrointestinal $e$ manterem-se vivas, com a finalidade de melhorar a saúde do hospedeiro. Segundo o mesmo autor, existem microorganismos denominados bioremediadores, os quais atuam na qualidade da água, e microorganismos denominados biocontroladores, sendo esses usados como antagônicos ao crescimento de organismos patogênicos. As bactérias probióticas estão inseridas no grupo dos biocontroladores. De acordo com Vieira et al. (2000), as bactérias probióticas tem potencial para substituir os antibióticos por não poluir o ambiente, não selecionar cepas resistentes, além de possibilitar um melhor crescimento de pós-larvas de camarão em laboratório.

As bactérias do gênero Bacillus têm sido usadas como probiótico nos cultivos de camarão, atuando como um biocontrole para reduzir a carga de víbrios no hospedeiro e no ambiente de cultivo (Rengpipat et al., 2000). Algumas espécies de Bacillus são facilmente encontradas em sedimentos marinhos e naturalmente presentes nas brânquias, cutícula e trato intestinal de organismos bentônicos, tais como os camarões (Sharmila et al., 1996). A partir de estudos sobre a utilização de bactérias probióticas no cultivo do L. vannamei, Gullian \& Rodríguez (2002) evidenciaram que as bactérias benéficas da microflora intestinal são competidoras em potencial de cepas patogênicas.

$\mathrm{Na}$ larvicultura de camarões peneídeos, embora exista um consenso sobre os benefícios da redução ou eliminação do uso de antibióticos em substituição ao emprego de probióticos nos tanques de cultivo, as informações ainda são dispersas e dependem principalmente das recomendações dos fabricantes destes produtos. Neste sentido, o presente estudo teve como objetivo comparar o efeito da utilização de probiótico e antibiótico no cultivo de pós-larvas do camarão branco L. vannamei.

\section{MATERIAIS E MÉTODOS}

\section{Procedência dos animais}

As pós-larvas utilizadas no experimento foram obtidas no setor de larvicultura da empresa Netuno, localizada em Sirinhaém, Pernambuco. Larvas no estágio de $\mathrm{Mísis}_{3}$ foram mantidas em um tanque de 80 litros de volume útil sob aeração constante, temperatura de $28^{\circ} \mathrm{C}$ e salinidade 34 . A alimentação consistiu de ração comercial para $L$. vannamei (INVEFrippak, 2CD) ofertada a cada duas horas e náuplios de Artemia congelados ofertados ad libitum uma vez ao dia (18:00h). A microalga Chaetoceros calcitrans foi mantida no tanque na concentração de $12 \times 10^{4}$ células $\mathrm{ml}^{-1}$. Quando atingiu o estágio de $\mathrm{PL}_{1}$ (1 dia de vida na fase de pós-larva), os animais foram transferidos para as parcelas experimentais.

\section{Delineamento experimental}

$\mathrm{O}$ experimento foi inteiramente casualizado e consistiu de três tratamentos com quatro repetições cada, correspondendo a um tratamento biológico (TB), onde foi adicionado probiótico (Bacillus spp.), tratamento químico (TQ), com adição de antibiótico (eritromicina e formalina) e controle (TC), sem adição de nenhum produto na água de cultivo.

Foram utilizados como parcelas experimentais potes plásticos com volume útil de 5 litros, onde 50 pós-larvas $\mathrm{L}^{-1} \quad\left(\mathrm{PL}_{1}\right)$ foram estocadas em cada recipiente. A água utilizada no experimento foi previamente filtrada $(0,5 \mu \mathrm{m})$ e clorada (15 ppm) por 24 horas, sendo desclorada através da utilização de acido ascórbico (5 ppm). As parcelas experimentais foram distribuídas de forma aleatória em sala com fotoperíodo controlado (12h claro: 12h escuro). Uma aeração suave com pedra porosa foi mantida constantemente em cada recipiente.

No tratamento TB foi adicionado diariamente na água de cultivo 1 ppm de probiótico comercial (INVE Sanolife $\left.{ }^{\circledR} \mathrm{MIC}\right)$, contendo cepas de Bacillus subtilis, $B$. licheniformis e $B$. pumilus na concentração de $5 \times 10^{10}$ UFC $\mathrm{g}^{-1}$, conforme recomendado pelo fabricante. No tratamento $\mathrm{TQ}$ a eritromicina foi 
utilizada como substância antibiótica, sendo que 1 ppm foi adicionado na água apenas no primeiro dia do experimento e, a partir do segundo dia, foi adicionada formalina diariamente na quantidade de $10 \mathrm{ppm}$. A água de todos os tratamentos teve uma renovação diária de $10 \%$.

A alimentação consistiu de rações comerciais (INVE-Frippak 3CD e INVE-Frippak PL+300) ofertada dez vezes ao dia (a cada duas horas), em quantidade pré estabelecida pelo fabricante para esta fase de desenvolvimento, e 15 náuplios de Artemia por póslarva ofertados duas vezes ao dia (16:00 e 20:00 h). A microalga Chaetoceros calcitrans foi mantida nos tratamentos na concentração de $12 \times 10^{4}$ células $\mathrm{ml}^{-1}$.

Durante o experimento, os seguintes parâmetros de qualidade de água: temperatura, oxigênio dissolvido, $\mathrm{pH}$ e salinidade foram monitorados diariamente através de um medidor multiparâmetro (YSI 556). As concentrações dos compostos nitrogenados nitrito $\left(\mathrm{NO}_{2}\right)$ e amônia $\left(\mathrm{NH}_{3}\right)$ foram medidas no primeiro, quinto e décimo dia de experimento através de um fotocolorímetro (ALFAKIT-AT10P).

O experimento foi finalizado após 10 dias quando os camarões atingiram o estágio de $\mathrm{PL}_{10}$. Nesta oportunidade, pós-larvas foram quantificadas para determinação da sobrevivência (\%), e o peso final $(\mathrm{mg})$ foi obtido através da pesagem conjunta de 100 animais de cada parcela experimental em uma balança de precisão $(0,0001 \mathrm{~g})$, após a remoção do excesso de umidade em papel absorvente. Para avaliação do comprimento total (medida entre as extremidades do rostro e do telson, $\mathrm{mm}$ ), 15 animais de cada parcela experimental foram medidos com um paquímetro digital.

\section{Análise bacteriológica}

A concentração presuntiva de bactérias do gênero Vibrio na água de cultivo e no camarão foi monitorada no primeiro e último dia do experimento, sendo a água inicial analisada antes do povoamento das parcelas experimentais. Para estimar a concentração destas bactérias na água foram realizadas diluições seriadas decimais das amostras das parcelas experimentais em solução salina esterilizada $(3,5 \% \mathrm{NaCl})$ e posterior plaqueamento de uma alíquota de $0,1 \mathrm{~mL}$ de cada diluição em meio seletivo Agar TCBS (Agar TCBS, Himedia). Após o período de incubação de $24 \mathrm{~h}$ em estufa a $30^{\circ} \mathrm{C}$, foi feita a contagem das unidades formadoras de colônias (UFC ml ${ }^{-1}$ ) nas placas que apresentaram entre 25 e 250 colônias (Downes \& Ito, 2001).

Para contagem presuntiva de Vibrio nos animais, tanto a amostragem inicial, como a final, foi realizada pela amostra aleatória de 100 indivíduos, sendo a primeira feita antes da estocagem dos tratamentos e a segunda nas parcelas experimentais ao término do experimento. As amostras de camarão foram lavadas com água destilada esterilizada, seguida de solução salina esterilizada $(3,5 \% \mathrm{NaCl})$ para remoção das bactérias externas. Em seguida as amostras foram maceradas, diluídas e plaqueadas, seguindo a mesma metodologia descrita para a análise de água.

\section{Análise dos dados}

Para determinar diferenças significativas entre os tratamentos, os valores dos parâmetros de qualidade de água, peso, comprimento, sobrevivência e concentração de Vibrio spp. foram submetidos à análise de variância (ANOVA) levando em consideração as premissas necessárias. $O$ teste Tukey de comparação de médias foi utilizado para determinar diferenças significativas entre os tratamentos $(p<0,05)$ (Mendes, 1999). As análises estatísticas foram realizadas com 0 auxílio do programa Statistica 7.0.

\section{RESULTADOS}

Os parâmetros de qualidade de água não diferiram significativamente entre os tratamentos. Os valores médios e erros padrões ( \pm EP) dos dados agrupados apresentaram temperatura de $28,2 \pm 0,2^{\circ} \mathrm{C}$, $\mathrm{pH}$ de $8,25 \pm 0,01$ e oxigênio dissolvido de 5,0 $\pm 0,05$ $\mathrm{mg} \mathrm{L}^{-1}$. A salinidade de todos os tratamentos foi mantida em 34. A amônia $\left(\mathrm{NH}_{3}\right)$ e o nitrito $\left(\mathrm{NO}_{2}\right)$ apresentaram valores médios gerais de $0,92 \pm 0,14 \mathrm{mg}$ $\mathrm{L}^{-1}$ e $0,02 \pm 0,004 \mathrm{mg} \mathrm{L}^{-1}$, respectivamente (Tabela 1 ). 
TABELA 1 - Valores finais médios ( $\pm \mathrm{EP})$ de temperatura, $\mathrm{pH}$, oxigênio dissolvido, salinidade, amônia $\left(\mathrm{NH}_{3}\right)$ e nitrito $\left(\mathrm{NO}_{2}\right)$ de pós-larvas $\left(\mathrm{PL}_{10}\right)$ do camarão $L$. vannamei cultivados nos tratamentos biológico (TB), químico (TQ) e controle (TC).

\begin{tabular}{|c|c|c|c|}
\hline Variáveis & Tratamentos & & \\
\hline & TB & $T Q$ & TC \\
\hline Temperatura $\left({ }^{\circ} \mathrm{C}\right)$ & $28,16 \pm 1,17^{\mathrm{a}}$ & $28,36 \pm 1,05^{\mathrm{a}}$ & $28,19 \pm 1,05^{\mathrm{a}}$ \\
\hline $\mathrm{pH}$ & $8,26 \pm 0,06^{\mathrm{a}}$ & $8,24 \pm 0,06^{\mathrm{a}}$ & $8,26 \pm 0,06 a$ \\
\hline Oxigênio Dissolvido $\left(\mathrm{mg} \mathrm{L}^{-1}\right)$ & $4,98 \pm 0,29^{a}$ & $5,01 \pm 0,35^{a}$ & $4,91 \pm 0,49^{a}$ \\
\hline Salinidade & $34,3 \pm 0,48^{a}$ & $34,3 \pm 0,48^{\mathrm{a}}$ & $34,3 \pm 0,48^{a}$ \\
\hline Amônia $\left(\mathrm{NH}_{3}\right)$ & $0,91 \pm 0,16^{\mathrm{a}}$ & $0,95 \pm 0,07^{\mathrm{a}}$ & $0,91 \pm 0,17^{\mathrm{a}}$ \\
\hline Nitrito $\left(\mathrm{NO}_{2}\right)$ & $0,02 \pm 0,01^{a}$ & $0,01 \pm 0,00^{\mathrm{a}}$ & $0,02 \pm 0,01^{\mathrm{a}}$ \\
\hline
\end{tabular}

Letras distintas na mesma linha indicam diferenças significativas $(\mathrm{p}<0,05)$.

Para as variáveis peso e comprimento dos camarões, não foram observadas diferenças significativas entre os tratamentos (Tabela 2).

TABELA 2 - Valores finais médios ( \pm EP) do peso $(\mathrm{mg})$, comprimento $(\mathrm{mm})$ e sobrevivência $(\%)$ de pós-larvas $\left(\mathrm{PL}_{10}\right)$ do camarão $L$. vannamei cultivados nos tratamentos biológico (TB), químico (TQ) e controle (TC).

\begin{tabular}{llll}
\hline Variáveis & Tratamentos & & \\
\hline & TB & TQ & TC \\
\cline { 2 - 4 } Peso & $2,31 \pm 0,09^{\mathrm{a}}$ & $2,67 \pm 0,07^{\mathrm{a}}$ & $2,39 \pm 0,02^{\mathrm{a}}$ \\
Comprimento & $7,55 \pm 0,10^{\mathrm{a}}$ & $7,58 \pm 0,14^{\mathrm{a}}$ & $7,68 \pm 0,12^{\mathrm{a}}$ \\
Sobrevivência & $77,7 \pm 1,1^{\mathrm{a}}$ & $75,9 \pm 1,75^{\mathrm{a}}$ & $74,8 \pm 1,5^{\mathrm{a}}$ \\
\hline
\end{tabular}

Letras distintas na mesma linha indicam diferenças significativas $(p<0,05)$.

A análise bacteriológica inicial não constatou a presença presuntiva de Vibrio spp. na água de cultivo, entretanto, as pós-larvas $\left(\mathrm{PL}_{1}\right)$ apresentaram uma concentração média de $11,54 \times 10^{6}$ UFC $\mathrm{g}^{-1}$. Para a análise bacteriológica final, a concentração presuntiva de Vibrio spp. na água de cultivo dos tratamentos TB e TQ não apresentaram diferenças significativas entre si, no entanto, os mesmos apresentaram valores significativamente inferiores quando comparados com o tratamento TC (Tabela 3).

TABELA 3 - Valores finais médios ( \pm EP) da concentração presumível de Vibrio spp. na água de cultivo (UFC $\mathrm{mL}^{-}$ ${ }^{1}$ ) e nas pós-larvas (UFC g ${ }^{-1}$ ) do camarão L. vannamei cultivados nos tratamentos biológico (TB), químico (TQ) e controle (TC).

\begin{tabular}{|c|c|c|c|}
\hline Concentração de Vibrio spp. & Tratamentos & & \\
\hline & TB & $T Q$ & TC \\
\hline Água & $2,51 \pm 0,18 \times 10^{4 a}$ & $2,72 \pm 0,32 \times 10^{4 a}$ & $4,12 \pm 0,26 \times 10^{4 b}$ \\
\hline Pós-larvas & $0,71 \pm 0,31 \times 10^{6 a}$ & $4,22 \pm 1,58 \times 10^{6 b}$ & $7,92 \pm 3,27 \times 10^{6 b}$ \\
\hline
\end{tabular}

Letras distintas na mesma linha indicam diferenças significativas $(p<0,05)$.

Com relação à quantidade presuntiva de Vibrio spp. nas pós-larvas ao final do experimento, o tratamento TB apresentou uma concentração significativamente inferior em comparação com os tratamentos TQ e TC, os quais não diferiram entre si (Tabela 3). 


\section{DISCUSSÃO}

Os parâmetros de temperatura e salinidade obtidos nesse estudo estiveram dentro das faixas adequadas para o cultivo de pós-larvas do camarão L. vannamei, recomendadas por Ponce-Palafox et al. (1997). Estes autores observaram que o cultivo de pós-larvas em temperaturas entre 28 a $30^{\circ} \mathrm{C}$ e salinidades entre 33 a 40 resultou em melhores taxas de sobrevivência e crescimento para a espécie. Da mesma forma, o oxigênio dissolvido, pH, amônia e nitrito registrados no presente estudo estiveram de acordo com o recomendado para o cultivo de camarões (Boyd, 1990).

A sobrevivência das pós-larvas no tratamento com adição de probiótico (Bacillus spp.) na água não diferiu dos demais tratamentos testados. Este resultado corrobora com o estudo realizado por Guo et al. (2009) para $P$. monodon, onde a adição diária de $B$. fusiformis na água $\left(10^{5} \mathrm{UFC} \mathrm{mL}^{-1}\right)$ durante os estágios Zoea ${ }_{1}$ e $\mathrm{PL}_{1}$, não resultou em diferença significativa na taxa de sobrevivência $(88,7 \%)$ quando comparado com o tratamento controle $(73,3 \%)$. Entretanto, estes autores observaram que quando o mesmo procedimento foi realizado na larvicultura de L. vannamei, houve uma maior sobrevivência no tratamento com adição de B. fusiformis $(87,9 \%)$, o qual diferiu significativamente do controle $(41,2 \%)$. Os autores sugerem que esta baixa sobrevivência das larvas sem adição de $B$. fusiformis ocorreu devido à presença de espécies de Vibrio na larvicultura.

Os valores de ganho de peso encontrados no presente estudo não apresentaram diferenças significativas entre os tratamentos, entretanto, ZiaeiNejad et al. (2006) observaram que o camarão Fenneropenaeus indicus cultivados com probiótico (Bacillus spp.), entre os estágios de Mísis ${ }_{1}$ a $\mathrm{PL}_{14}$, apresentou um maior ganho de peso quando comparado com o tratamento sem uso de probiótico. Por outro lado, esses autores não observaram diferenças significativas quanto ao comprimento dos camarões, o que está de acordo com os resultados desse estudo. $\mathrm{Em}$ estudo similar onde se cultivou $L$. vannamei de náuplio até $\mathrm{PL}_{10}$ verificou-se uma menor sobrevivência do tratamento sem adição de produto na água, enquanto que não houve diferença estatística entre as sobrevivências dos tratamentos com adição de probiótico Sanolife ${ }^{\circledR}$ e com adição de antibiótico e formaldeído (Decamp et al., 2008). No presente estudo, a não diferença entre a sobrevivência do tratamento sem adição de produtos na água em relação aos outros tratamentos se deve, possivelmente, ao menor tempo de cultivo em comparação ao trabalho realizado por Decamp et al. (2008).

Os tratamentos TQ e TC apresentaram uma concentração mais elevada de Vibrio spp. no camarão do que o tratamento $\mathrm{TB}$, porém, esta maior concentração não afetou a sobrevivência dos mesmos. Em muitos casos, os víbrios são oportunistas, causando doenças e mortalidades em animais apenas quando esses se encontram fisiologicamente estressados (Alderman \& Hastings, 1998). Provavelmente, os resultados obtidos para o crescimento e sobrevivência, os quais não diferiram entre os tratamentos, se deve a manutenção de condições ambientais e alimentares adequadas durante o experimento, onde os camarões não foram submetidos ao estresse fisiológico. De acordo com Rengpipat et al. (2000), a redução do estresse pode ser usada para aumentar a resistência dos camarões a doenças, sendo que estresse causado pela má qualidade de água, por exemplo, pode deixar os camarões suscetíveis aos patógenos presentes no meio. Os resultados obtidos no presente estudo também podem estar relacionados ao fato de que nem todas as bactérias do gênero Vibrio são nociva, e portanto não afetam o desempenho dos camarões cultivas (Gomez-Gil et al., 1998).

A redução da concentração inicial de Vibrio spp. nas larvas de $11,54 \times 10^{6}$ para $0,71 \times 10^{6}$ UFC g $^{-1}$ ao final do experimento com utilização de probiótico está provavelmente relacionada com a atividade das bactérias do gênero Bacillus, as quais são capazes de competir com outras bactérias por nutrientes e espaço, como também podem excluir outras bactérias através da produção de antibióticos (Moriarty, 1998; Verschuere et al., 2000). Em experimento conduzido in vitro, a atividade inibitória de bactérias do gênero Bacillus contra as do gênero Vibrio foi avaliada em meio TCBS, indicando que cepas de $B$. subtilis, $B$. licheniformis e outras espécies mostraram atividade inibitória contra um grande número de cepas de Vibrio (Decamp et al., 2008). Estes autores também 
compararam a adição de probiótico (Bacillus spp.) com um tratamento profilático (antibiótico) e um controle, no cultivo de $P$. monodon entre os estágios de Náuplio e $\mathrm{PL}_{10}$. Os resultados indicaram que a adição de probiótico ou antibiótico diminuiu consideravelmente a concentração de Vibrio spp. na água em comparação com o tratamento sem estes produtos, o que corrobora com os resultados observados no presente estudo.

Os resultados obtidos nesse estudo indicaram que a utilização de antibiótico através da água de cultivo parece não ser eficiente contra o crescimento de Vibrio spp. nas pós-larvas de L. vannamei. Outro fato relevante é que os antibióticos podem favorecer o surgimento de bactérias resistentes a esses medicamentos, podendo ocorrer ineficiência desses até mesmo na água onde os animais estão sendo cultivados (Defoirdt et al., 2007). Costa et al. (2008) detectaram cepas de Vibrio multiresistentes aos antibióticos, coletadas nas águas e nos camarões $L$. vannamei cultivados em fazendas no estado do Ceará, Brasil.

\section{CONCLUSÃO}

O uso de probiótico ou antibiótico no cultivo de pós-larvas de $L$. vannamei não influenciou no crescimento e sobrevivência dos animais, entretanto, a adição de probiótico foi mais eficiente para a diminuição da concentração de possíveis bactérias patógenas do gênero Vibrio, tanto na água como nas pós-larvas cultivadas. Sugere-se que o emprego do probiótico Bacillus spp. é adequado para substituir a utilização de antibióticos e outras substâncias químicas como a formalina no cultivo de pós-larvas de $L$. vannamei, devido aos possíveis benefícios para a sanidade das pós-larvas cultivadas, além de seguir princípios de aquicultura responsável.

\section{REFERÊNCIAS}

ALDERMAN, D.J.; HASTINGS, T.S. 1998. Antibiotic use in aquaculture: development of antibiotic resistance - potential for consumer health risks. Int. J. Food Sci. Technol., v.33, p.139-155.

BOYD, C.E. 1990. Water quality in ponds for aquaculture. Alabama Agricultural Experimental Station, Auburn University, Auburn, AL, 482p.

COSTA, R.A. ; HITZSCHKY, G. ; VIEIRA, F ; SILVA, G.C. ; VIEIRA, R.H.S.F.; SAMPAIO, S.S. 2008. Susceptibilidade "in vitro" a antimicrobianos de estirpes de Vibrio spp. isoladas de camarões (Litopenaeus vannamel) e de água de criação destes animais provenientes de uma fazenda de camarões no Ceará Nota prévia. Braz. J. Vet. Res. Anim. Sci., v.45, n.6, p.458-462.

DECAMP, O.; MORIARTY, D.J.W.; LAVENS, P. 2008. Probiotics for shrimp larviculture: review of field data from Asia and Latin America. Aquac. Res., v.39, p.334-338.

DEFOIRDT, T.; BOON, N.; SORGELOOS, P.; VERSTRAETE, W.; BOSSIER, P. 2007. Alternatives to antibiotics to control bacterial infections: luminescent vibriosis in aquaculture as an example. Trends Biotechnol., v.25, p.472-479.

DOWNES, M. P.; ITO, K. 2001. Compendium of Methods for the Microbiological Examination of Foods. American Public Health Association (APHA), 4th edition, 600p.

GATESOUPE, F.J. 1999. The use of probiotics in aquaculture. Aquaculture, v.180, p.147-165.

GOMEZ-GIL, B.; ROQUE, A.; TURNBULL, J.F. 2000. The use and selection of probiotic bacteria for use in the culture of larval aquatic organisms. Aquaculture, v.191, p.259-270.

GOMEZ-GIL, B.; TRON-MAYÉN, L.; ROQUE, A.; TURNBULL, J.F.; INGLIS, V.; GUERRA-FLORES, A.L. 1998. Species of Vibrio isolated from hepatopancreas, haemolymph and digestive tract of a population of healthy juvenile Penaeus vannamei. Aquaculture, v.163, p.1-9.

GULLIAN, M.; RODRíGUEZ, J. 2002. Estudio de las cualidades inmunoestimulantes de nuevas bacterias probióticas asociadas al cultivo de Litopenaeus vannamei. Manejo de enfermidades em camarones. In: Congreso Ecuatoriano de Acuicultura, 6., Ecuador. Anais do Congreso Ecuatoriano de Acuicultura, p.47-49.

GULLIAN, M.; THOMPSON, F.; RODRIGUEZ, J. 2004. Selection of probiotic bacteria and study of their immunostimulatory effect in Penaeus vannamei. Aquaculture, v.233, p.1-14.

GUO, JJ. ; LIU, KF.; CHENG, SH.; CHANG, Cl.; LAY, JJ.; HSU, YO.; YANG, JY.; CHEN, TI. 2009. Selection of probiotic bacteria for use in shrimp larviculture. Aquac. Res., v.40, p.609-618.

LEE, KK.; YU, SR.; CHEN, FR.; YANG, TI.; LIU, PC. 1996. Virulence of Vibrio alginolyticus isolated from diseased tiger prawn, Penaeus monodon. Curr. Microbiol., v.32, p.229-231.

LIGHTNER, D.V. 1993. Diseases of cultured penaeid shrimp. In: MCVEY, J.P. CRC Handbook of Mariculture: Crustacean Aquaculture, FL, v.1, p.393-486.

MENDES, P. P. 1999. Estatística aplicada à aqüicultura. Recife: Bagaço, v. 1. $265 \mathrm{p}$.

MORIARTY, D.J.W. 1998. Control of luminous Vibrio species in penaeid aquaculture ponds. Aquaculture, v.164, p.351-358.

MORIARTY, D.J.W. 1999. Disease control in shrimp aquaculture with probiotic bacteria. In: BELL, C.R.; BRYLINSKY, M.; JOHNSON-GREEN, P. (Eds.). Proceedings of the 8th International Symposium on Microbial Ecology. Atlantic Canada Society for Microbial Ecology, Halifax, Canada, p. 237-243.

PONCE-PALAFOX, J.; MARTINEZ-PALACIOS, C.A.; ROSS, L.G. 1997. The effects of salinity and temperature on the growth and survival rates of juvenile white shrimp, Penaeus vannamei, Boone, 1931. Aquaculture, v.157, p.107-115.

RAVI, A.V.; MUSTHAFA, K.S.; JEGATHAMMBAL, G.; KATHIRESAN, K.; PANDIAN, S.K. 2007. Screening and evaluation of probiotics as a biocontrol agent against pathogenic Vibrios in marine aquaculture. Lett. Appl. Microbiol., v.45, p.219-223. 
RENGPIPAT, S.; RUKPRATANPORN, S.; PIYATIRATITIVORAKUL, S.; MENASAVETA, 2000. P. Immunity enhancement in black tiger shrimp (Penaeus monodon) by a probiont bacterium (Bacillus S11). Aquaculture, v.191, p.271-288.

RUANGPAN, L.; KITAO, T. 1991. Vibrio bacteria isolated from black tiger prawn, Penaeus monodon Fabricius. J. Fish Dis., v.14, p.383-388.

SHARMILA, R.; ABRAHAM, T.J.; SUNDARARAJ, V. 1996. Bacterial flora of semi-intensive pond reared Penaeus indicus (H.Milne Edwards) and the environment. J. Aquac. Tropics, v.11, p.193-203,.

VANDENBERGHE, J.; VERDONCK, L.; ROBLES-AROZARENA, R.; RIVERA, G.; BOLLAND, A.; BALLADARES, M.; GOMEZGIL, B.; CALDERON, J.; SORGELOOS, P.; SWINGS, J. 1999. Vibrios associated with Litopenaeus vannamei larvae, postlarvae, broodstock, and hatchery probionts. Appl. Environ. Microb., v.65, p.2592-2597.
VERSCHUERE, L.; ROMBAUT, G.; SORGELOOS, P.; VERSTRAETE, W. 2000. Probiotic Bacteria as Biological Control Agents in Aquaculture. Microbiol. Mol. Biol. R., v.64, p.655-671.

VIEIRA, R.H.S.F.; GESTEIRA, T.C.V.; MARQUES, L.C.; MARTINS, P.C.C.; MONTEIRO, C.M.; CARVALHO, R.L. 2000. Vibrio spp. e suas implicações sobre larviculturas de camarões marinhos. Arq. de Ciências do Mar, v.33, p.107-112.

WYBAN, J.A.; SWEENEY, J.N. 1991. Intensive shrimp production technology: the Oceanic Institute shrimp manual, USA, 158p.

ZIAEI-NEJAD, S.; REZAEI, M.H.; TAKAMI, G.A.; LOVETT, D.L.; MIRVAGHEFI, AR.; SHAKOURI, M. 2006. The effect of Bacillus spp. bacteria used as probiotics on digestive enzyme activity, survival and growth in the Indian white shrimp Fenneropenaeus indicus. Aquaculture, v.252, p.516-524

Submetido $-21 / 12 / 2011$

Aceito - 06/03/2012 
